\title{
Geochemical features of soils from the Mid-Ural ore deposit
}

\author{
Ekaterina Dziuba*, Dmitriy Andreev, Sergey Buzmakov, and Yuliya Khotyanovskaya \\ Perm State University, Department of Biogeocenology and Nature Protection, Bukireva str., 15, \\ Perm, Russia
}

\begin{abstract}
This paper deals with the contemporary state of soil cover around the Mid-Ural iron ore deposit, focusing on geochemical features. Sample plots were laid based on the technogenic impact in the study area. Soil samples were taken in the zone of the iron ore deposit, in the zones of overburden and gold mining waste dumps influence, and in the rock blasting site. A total of 64 sample plots were laid. Soil samples were sampled incrementally by an envelope method from a depth of $0.00-0.03 \mathrm{~m}$. Soil texture, physicochemical features, and total heavy metal content $(\mathrm{V}, \mathrm{Mn}, \mathrm{Ni}$, $\mathrm{Cu}, \mathrm{Zn}, \mathrm{As}, \mathrm{Cd}$, and $\mathrm{Pb}$ ) were defined for the soil samples. As a result, the evaluation of heavy metal soil pollution under the influence of iron ore deposit mining is given. Chemical contamination of soil was assessed by a cumulative chemical contamination index. Geochemical series of elements formed under the influence of iron ore deposit mining, as well as overburden and gold mining are given. Here, geochemical patterns of heavy metal distribution in the soil of iron ore deposit and under the gold mining influence are considered. The analysis of gold mining influence on the elementary composition of soil revealed the anomalous content of $\mathrm{Mn}$ and Ni.
\end{abstract}

\section{Introduction.}

The Vernadsky law for global dissipation of chemical elements states that all environments have all the elements, but their distribution is uneven and highly irregular [1]. Knowledge of the chemical content in an investigated system or object can provide solutions to various environmental problems. Soil is a very important subject of investigation related to this problem [2-5].

The technogenic transformation of a natural environment is the change of environmental compartments and natural systems caused by industrial activity. The transformation involves changing the biosphere and its components (ecosystems) under the influence of geochemical processes, and comprise human, technical, and technological activities for extracting, concentrating, and relocating minerals and organic compounds $[6,7]$.

The entry of heavy metals (HMs) into the environment is driven by human activity, and the mining industry is one industry that pollutes the environment with heavy metals.

\footnotetext{
* Corresponding author: aea_eco@mail.ru
} 
Compounds with heavy metals contaminate air, water, and soil, and can enter the bodies of plants and animals [8].

Explored mineral deposits are actual sources of environmental pollution [9]. Metalliferous deposits, which contain set of components controlled in human living environments, pose a potential threat for the environment. These components are extracted incompletely, and the residuals are piled in waste dumps [10].

Soil serves as a good scavenger for HMs, and occupies a significant niche in the cycle of pollutants in the biosphere [11]. It is already known that metals accumulate in soil in a relatively short period, and they are withdrawn from the soil at an extremely slow rate $[12,13]$.

The concentration of HMs is affected by soil properties. Heavy textured soils generally have higher HM concentration, while sandy and sandy loam soils accumulate HMs to a lesser extent. Acid-base soil properties have a significant influence on these characteristics. In acidic conditions, insoluble parts of the HM fraction becomes soluble, resulting in an increased concentration of HMs in acidic soils [14].

The Sverdlovsk region is one of the oldest mining regions in Russia and one of the largest in the Russian Federation in terms of proven and projected ore mineral reserves. This resulted in an intense growth in mining (including gold mining), iron, steel, and non-ferrous metal industries, as well as construction and chemical industries [15].

Mining and smelting waste contains a significant quantity of non-ferrous, ferrous, rare, and trace metals. This waste represents a technogenic material that was piled and accumulated because there were no cost effective and environmentally friendly technologies for its utilization and recycling. During permanent storage of mining waste, several processes occur, such as geochemical transformation with the generation of new technogenic minerals, depletion of valuable metals, removal of elements out of the storage sites, and environmental pollution events [16].

The aim of the research was to reveal special aspects of soil pollution in the Mid-Ural ore deposit. The characteristics of soil cover are given, using the results of a summer field survey with soil type recognition and soil sampling for chemical analysis.

\section{Materials and methods.}

A field investigation of soil cover was conducted using the methodological recommendations on revelation of degraded and contaminated lands [17] and the instructional guidelines on risk assessment of soil contamination with chemical substances [18]. Typical terrain compartments were selected during a route survey where soil pits down to bedrock were located.

Soil sampling took place for assessment of quality and the level of pollution. Sample plots (20-25 $\mathrm{m}^{2}$ ) were laid out according to relief, geomorphological, and landscape features. Soil was sampled incrementally using an envelope method from a depth of $0.0-0.3 \mathrm{~m}$. The samples were then mixed together, giving a composite sample with a weight of at least $1 \mathrm{~kg}$.

Chemical contamination of soil was evaluated using the Total Chemical Pollution Index, which serves as an indicator of harmful health impact. The following indices were applied for the control of soil state: total microelement content ( $\mathrm{V}, \mathrm{Mn}, \mathrm{Ni}, \mathrm{Cu}, \mathrm{Zn}, \mathrm{As}, \mathrm{Cd}$, and $\mathrm{Pb}$ ), $\mathrm{pH}$, total humus, hydrolytic and exchangeable acidity, exchangeable hydrogen and $\mathrm{Al}$, exchangeable base (Ca, Mg, and S-value), degree of base saturation, labile phosphorus, and particle-size distribution.

Calculations related to the local geochemical background were conducted according to a guideline [19-22] as well as other specifications and literature sources [23,24]. For this purpose, the indices of microelement content in soil sampled within the Orefield were used. The fragments in the area with obvious anomalies were excluded from consideration. For 
instance, the content of an element that is vastly different from the typical value or fragments with technogenic pollution known beforehand would be excluded. The data from the remaining area, which could be characterized as an area with a mainly normal geochemical field were used in an element content sample compilation. This sample was laid on the basis of a local geochemical background evaluation.

A typical element content is defined by an average background content $\left(\mathrm{C}_{\mathrm{b}}\right)$ or geochemical background. A mean, $\mathrm{C}$, is taken as $\mathrm{C}_{\mathrm{b}}$ (normal probability law). For determination of the element content deviation in background samples from an average background value, a standard (mean-square) deviation value is used if the Gaussian law is considered.

For determination of a least value of chemical element content, which could be taken as exceeding background fluctuation limits with some probability, we used an anomaly threshold value. This parameter combines the background level with the standard deviation in case of normal distribution $\left(\mathrm{C}_{\mathrm{a}}=\mathrm{C}_{\mathrm{b}}+\mathrm{t}_{\mathrm{S}}\right)$. The probability that some value of this parameter could be exceeding background fluctuations depends on a coefficient. We used $t=1$ in the scope of this research.

General description of soil cover. The mountain group located in the eastern slope of the Ural Mountains in the northern part of the Middle Ural was investigated (Figure 1).

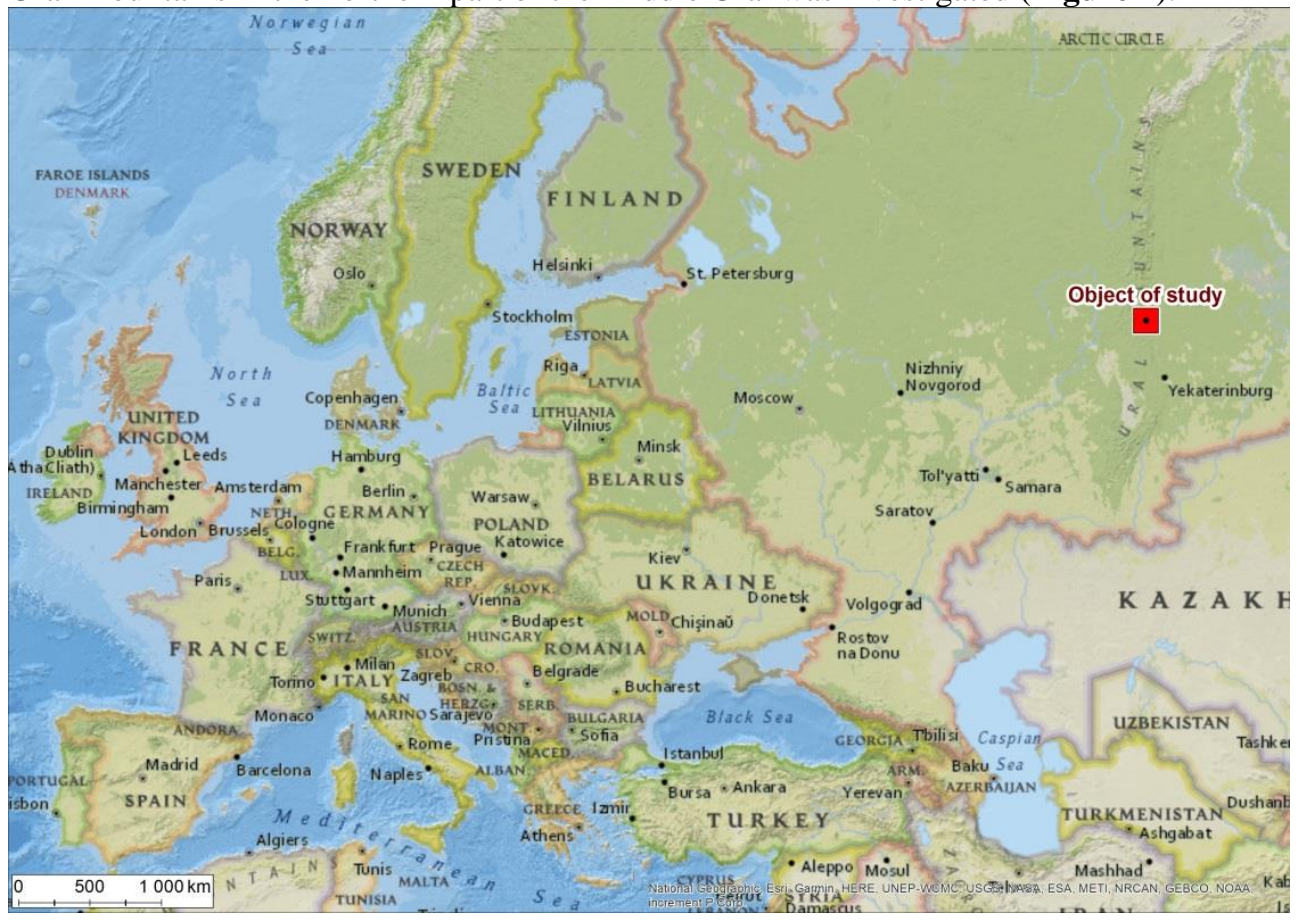

Fig. 1. Investigated area

This territory is classified as part of the Middle Ural Mountains province and is situated on the boundary between the Middle Ural low-mountain region and the eastern piedmont region, with taiga landscapes of mountain ranges and ridges on metamorphic and intrusive rocks. The landscape here is undulating, dissected with right tributaries of the Vyya River, Derevyannaya River, Chashchevitaya River, Rogalevka River, and others. Local forests are formed by both coniferous (pine, spruce, fir, and larch) and deciduous (birch, aspen, and linden) wood species. 
The soil cover of the area is characterized by heterogeneity caused by altitudinal zonation, diversity of rocks, and complexity of the landscape. The soils here are formed on eluvial and deluvial deposits underlaid by unstratified rocks that are gravelly and shallow.

The profile of mountain soils is negligibly differentiated and does not have a well-defined podzolic horizon. Accumulation of organic matter occurs in weakly mineralized underlayers and A1 horizon with dark brown humus spots and tongues. Underlying mass represents evenly coloured (usually dark brown or brownish) loam with debris inclusions.

The thickness of the fine-grained stratum in the profile is usually about $50-60 \mathrm{~cm}$. In the upper horizons, the gravel content is about $25 \%$, and it increases down the profile. The thickness of the fine-grained part of the soil profile decreases down to $30-40 \mathrm{~cm}$ or becomes fragmentary in steep slopes where rocks lie near the surface with increasing elevation. Upper parts of the slopes are associated with undifferentiated brown mountain forest soils. The mountain forest cambisols have several specific morphological and physicochemical indices that separate them from podzols and calcisols that are prevalent in the middle taiga zones.

\section{Results and discussion}

The distribution of the sample plots across the area investigated is shown in Fig. 2.

Soil texture. The given soils could be described as light (sandy loam) and heavy (from heavy loams to light clays) types. The increased content of coarse grains (1.0-0.25 mm and $0.25-0.05 \mathrm{~mm}$ ) down the profile is a specific feature of all mountain soils. Even distribution or some extent of accumulation of sludge (particles less than $0.01 \mathrm{~mm}$ ) and physical clay (particles less than $0.001 \mathrm{~mm}$ ) are clearly observed in the upper part of the profile compared to the mother rock as a result of the weakening of erosion and soil forming process with increasing depth. Thus, the soil forming process increases, and mountain relief conditions are accompanied by argillization of the upper horizons. In this regard, eluvial and deluvial profile differentiation, as for podzolic soils, does not occur.

Physical and chemical properties of soils. The soils of the area are acidic. Changes in acidity with depth is determined by the features of the mother rocks. Acidity of acidic rocks changes negligibly across the profile or increases downward. The upper horizons of all mountain soils have high exchangeable acidity, which is caused by hydrogen presence in organics and by exchangeable aluminium in mineral horizons. The soils also have high values of hydrolytic acidity. In upper organic horizons, these values reach $0.5 \mathrm{mg}$-equivalent/g and decrease dramatically with depth.

Cambisols differ from calcisols and podzols by specific content of exchangeable bases. These soils have an accumulation of exchangeable bases in the upper organic horizons and a steep decrease in their quantity in the mineral stratum. The minimum of exchangeable bases is consisted in soil-forming rock. The degree of base saturation seems to be constant across the profile, which explains the weak profile differentiation.

Forest cambisols are characterized by a high content of organic matter in the upper horizons and a gradual decrease with depth. The soils contain substantial amounts of humus across the whole profile.

Mountain forest saturated cambisols are close to neutral. They are distinguished by the saturation of absorbed bases, which declines with depth. The soils contain notable amounts of humus and have high hydrolytic acidity in the upper horizons. The upper portion contains more sludge and physical clay, while the lower mineral section is predominated by small and medium-sized sand. Acidic cambisol lessivage do not occur in the mountain forest. 


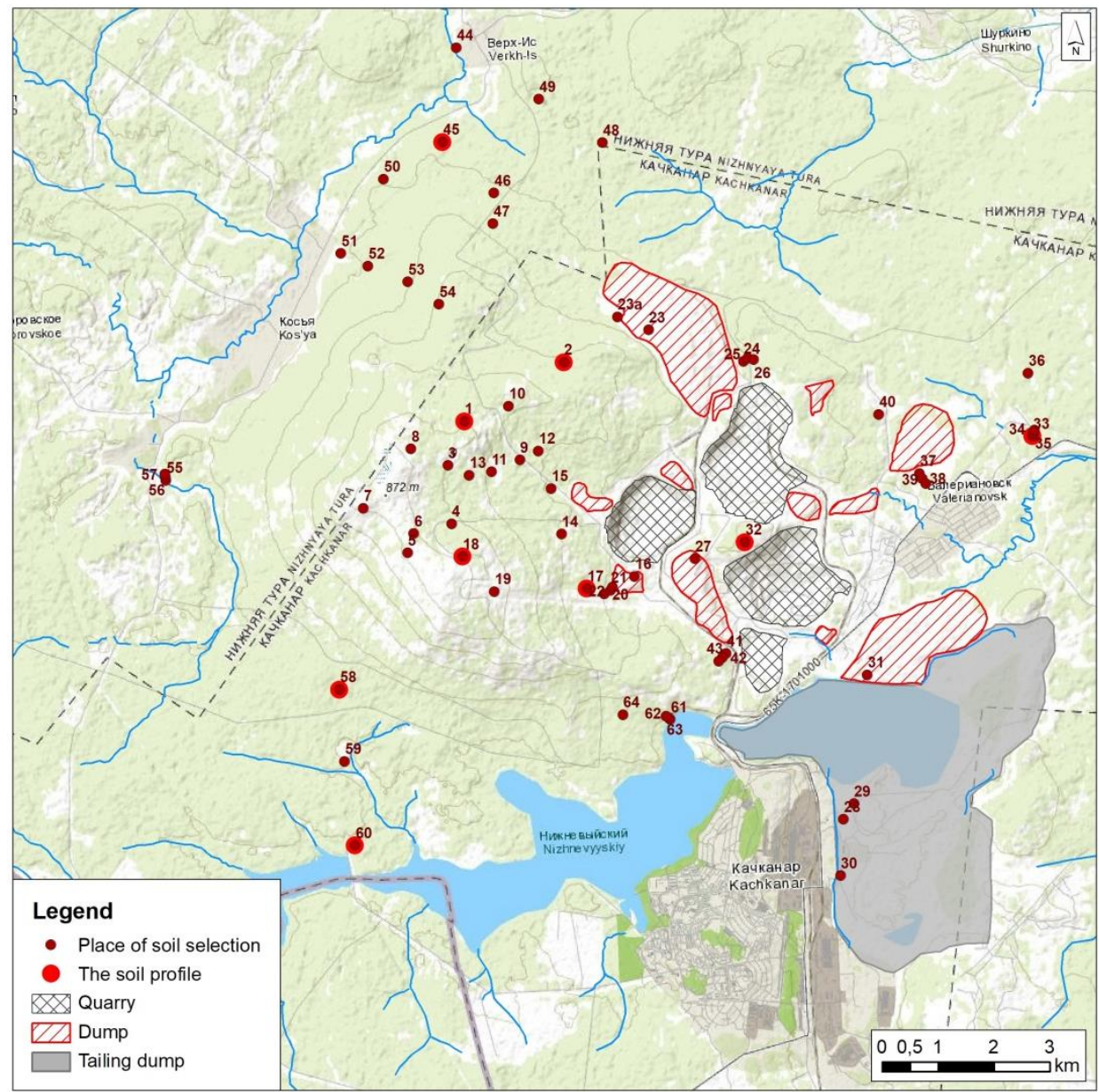

Fig. 2. The distribution of the sample plots (SP)

Low content of labile phosphorous could be noted for all the undisturbed mountain forest cambisols.

Calcisols were determined in the eastern and northern (Verkh-Is River) parts of the area. The soils with podzol features are formed in gentle slopes or poorly drained flat lands that receive additional moisture from water runoff. At heights of $328 \mathrm{~m}$ and $214-220 \mathrm{~m}$ in dark coniferous forests with moist conditions, gley podzols and calcisols are formed.

Calcisols are specified by high acidity and negligible content of exchangeable bases, accompanied with complete unsaturation of the medium part of the profile. Heavy texture and location within poorly drained lands provide consistent soil moisture, pseudoglazation, and partial accumulation of exchangeable bases relative to the upper part of the profile.

To sum up the data on undisturbed, natural soils of the investigated area, specific aspects of the pedogenic process should be noted. These are the prevalence of cambisols or mountain forest nonpodzolized soils accompanied by limited distribution of podzols. The morphology of the mountain soils is unique-it is negligibly differentiated and highly gravelly. Primitive accumulative soils of the upper parts of the slopes and mountain forest cambisols are formed due to xeromorphous pedogenesis and weathering conditions [25].

The close proximity of underlying dense rocks leads to insignificant soil differentiation and the absence of a clearly visible podzolic horizon. Reduced humidity of the mountain soils 
is due to water runoff and good rock permeability. These conditions make excessive moistening and reducing conditions impossible and provide for preserving iron in the soil profile. Iron stabilizes soil structure and preserves it from lessivage [26,27]. The intensity of weathering increases from the upper to lower relief components. Increases in moisture and soil depth down the slope lead to podsolization of forest cambisols. Such soils lose sandy fractions while the amount of coarse silt particles $(0.05-0.01 \mathrm{~mm})$ increases significantly. The distribution of clay fractions shows podzolic features, with their amounts decreasing in the podzolized horizon and increasing in the enrichment horizon. As the impact of mother rock on the soil disappears, it becomes similar to zonal calcisols [25].

The forest growth conditions could be considered to be quite favorable. The absence of podsolization and the close location of soil-forming rocks, often crystalline, provide considerable amounts of nutrients, while the strong structure of the soils creates good air and water conditions. However, significant earth grades and deforestation can create the conditions for severe erosion and rapid loss of all the soil cover.

Most of the published papers with data for background content of microelements in soil were based only on the research of zonal soils. Besides, the investigated area is characterized as the area of a geochemical anomaly since the large mineral deposits, in particular iron ores with high vanadium content, have been found here.

Based on the above considerations, there is a need for the determination of a local background. The local background is the average modal value of the geochemical index (or indices) of a given geological space (geological feature) and statistically acceptable interval of its variation [23].

The soils of the area were thoroughly sampled for the determination of the background values of microelement content. The results of the calculations are given in Table 1. The data is shown for the elements, with application in the calculation of Total Chemical Pollution Index.

Table 1. Calculations of the geochemical background values in soils

\begin{tabular}{|c|c|c|c|c|c|c|}
\hline $\begin{array}{c}\text { Chemical } \\
\text { element }\end{array}$ & $\begin{array}{c}\text { Maximum } \\
\text { value } \\
(\mathrm{mg} / \mathrm{kg})\end{array}$ & $\begin{array}{c}\text { Minimum } \\
\text { value } \\
(\mathrm{mg} / \mathrm{kg})\end{array}$ & $\begin{array}{c}\text { Background } \\
\text { value } \\
(\mathrm{mg} / \mathrm{kg})\end{array}$ & $\begin{array}{c}\text { Standard } \\
\text { deviation } \\
(\mathrm{mg} / \mathrm{kg})\end{array}$ & $\begin{array}{c}\text { Variation } \\
\text { coefficient } \\
(\%)\end{array}$ & $\begin{array}{c}\text { Minimum } \\
\text { anomaly value } \\
(\mathrm{mg} / \mathrm{kg})\end{array}$ \\
\hline $\mathrm{V}$ & 262.2 & 130.6 & 219.4 & 40.6 & 0.2 & 259.9 \\
\hline $\mathrm{Mn}$ & 995.5 & 339.2 & 674.4 & 183.1 & 0.3 & 857.5 \\
\hline $\mathrm{Ni}$ & 54.4 & 19.1 & 34.8 & 10.7 & 0.3 & 45.5 \\
\hline $\mathrm{Cu}$ & 56.9 & 17.7 & 29.3 & 12.4 & 0.4 & 41.6 \\
\hline $\mathrm{Zn}$ & 119.2 & 52.5 & 80.3 & 17.8 & 0.2 & 98.1 \\
\hline $\mathrm{As}$ & 12.0 & 5.1 & 7.7 & 2.0 & 0.3 & 9.7 \\
\hline $\mathrm{Cd}$ & 1.3 & 0.3 & 0.7 & 0.3 & 0.4 & 1.0 \\
\hline $\mathrm{Pb}$ & 64.5 & 13.3 & 29.3 & 17.3 & 0.6 & 46.6 \\
\hline
\end{tabular}

The maximum values for the content of the considered elements exceed the background values (Fig. 3). All the studied sample plots in the area of iron ore deposit were combined into 9 groups according to plant communities. For each of these groups, a geochemical series was constructed. We distinguish 5 groups according to the similarity of the geochemical series. Group 1 contains plot soils with mixed geochemical signature, where lithophiles (Mn and $\mathrm{V}$ ), chalcophiles ( $\mathrm{Zn}$ and $\mathrm{Cu}$ ), and siderophiles $(\mathrm{Ni})$ are prevalent. The mixed forest (SP 15, 17) with the series $\frac{M n}{707}>\frac{V}{353}>\frac{Z n}{83}>\frac{N i}{58}>\frac{C u}{54}>\frac{P b}{25}>\frac{A s}{10}>\frac{C d}{0.7}$ and the sparse spruce-birch forest (SP 19) with $\frac{M n}{996}>\frac{V}{262}>\frac{Z n}{77}>\frac{N i}{44}>\frac{C u}{19}>\frac{P b}{13}>\frac{A s}{5}>\frac{C d}{0.5}$ series fall under this group. 


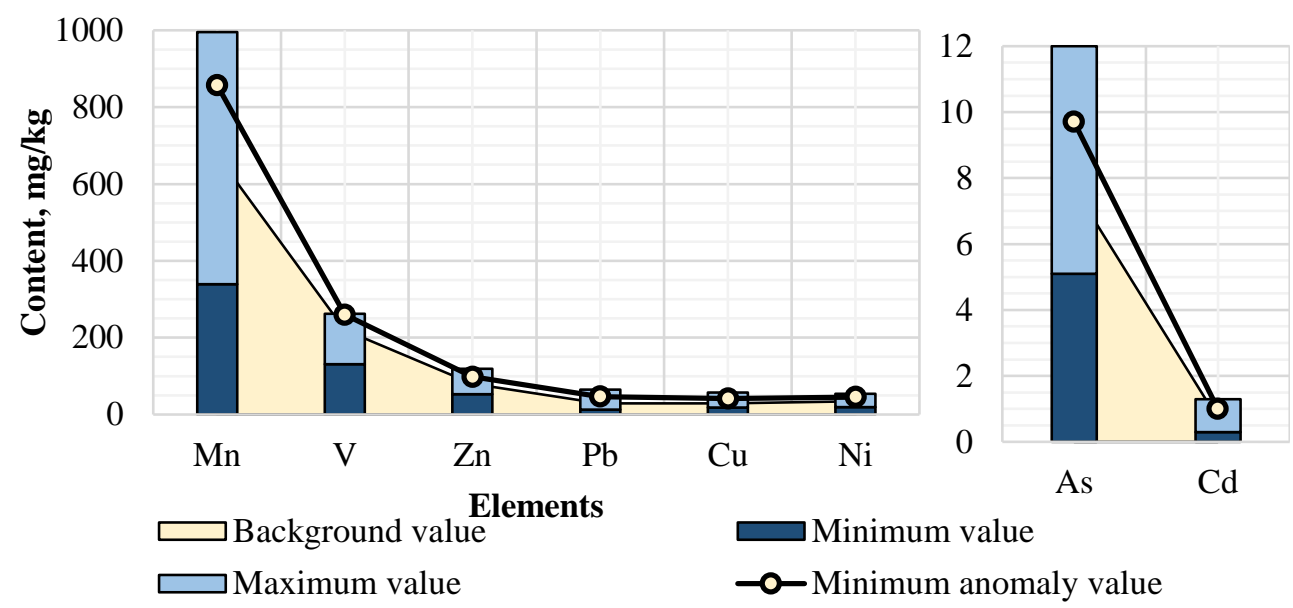

Fig. 3. The geochemical background values in soils

The geochemical series and mixed geochemical signatures of Group 2 and Group 1 are similar, but here we can see a greater content of $\mathrm{Pb}$ than $\mathrm{Cu}$. For the spruce-birch krummholz (SP 6, 8) the following series is characterized: $\frac{M n}{860}>\frac{V}{259}>\frac{Z n}{75}>\frac{N i}{39}>\frac{P b}{22}>\frac{C u}{19}>\frac{A s}{6.3}>\frac{C d}{0.6}$. While the sparse coniferous forest (SP 18) has the following series: $\frac{M n}{860}>\frac{V}{259}>\frac{Z n}{75}>\frac{N i}{39}>$ $\frac{P b}{22}>\frac{C u}{19}>\frac{A s}{6.3}>\frac{C d}{0.6}$.

Lithophiles ( $\mathrm{Mn}$ and $\mathrm{V}$ ) and chalcophiles $(\mathrm{Pb}$ and $\mathrm{Zn}$ ) are prevalent in group 3. It should be noted that Mn content significantly varies from $371 \mathrm{mg} / \mathrm{kg}$ to $741 \mathrm{mg} / \mathrm{kg}$. The soils of the spruce forest (SP 4) with the following series: $\frac{M n}{371}>\frac{V}{131}>\frac{Z n}{98}>\frac{P b}{56}>\frac{N i}{39}>\frac{C u}{31}>\frac{A s}{13}>\frac{C d}{1.3}$ have minimal content of Mn. The content of the elements is higher in the spruce-birch mixed forest (SP 14) with $\frac{M n}{741}>\frac{V}{244}>\frac{Z n}{132}>\frac{P b}{63}>\frac{N i}{47}>\frac{C u}{40}>\frac{A s}{12}>\frac{C d}{1.6}$ series, and the dark coniferous green moss forest (SP 9, 11-13) with

$\frac{M n}{643}>\frac{V}{209}>\frac{Z n}{92}>\frac{P b}{44}>\frac{N i}{32}>\frac{C u}{31}>\frac{A s}{9}>\frac{C d}{0.9}$ series.

The spruce green moss forest forming group 4 has the following series:

$\frac{M n}{660}>\frac{V}{235}>\frac{Z n}{69}>\frac{C u}{40}>\frac{N i}{25}>\frac{P b}{20}>\frac{A s}{7}>\frac{C d}{1}$. The sparse birch forest (group 5, SP 2), which has the following series: $\frac{V}{237}>\frac{M n}{229}>\frac{Z n}{53}>\frac{N i}{19}=\frac{C u}{19}>\frac{P b}{16}>\frac{A s}{6}>\frac{C d}{0.3}$, where V content is greatest but not exceeding Mn content in this site`s samples, has shown the biggest difference from other groups.

We calculated the Total Chemical Pollution Index for the territory of the iron ore deposit where pollutants exceed background values (Fig.4). This index was assessed relative to the background content of the elements in Ural soils $\left(\mathrm{Z}_{\mathrm{c}}\right)$ [25].

As for the background content, the Ural soils demonstrate the following: we can observe excess content in one sampling plot (spruce-birch mixed forest), while some plots` content approach but do not exceed an allowable level (spruce forest, mixed forest, dark coniferous green moss forest). 


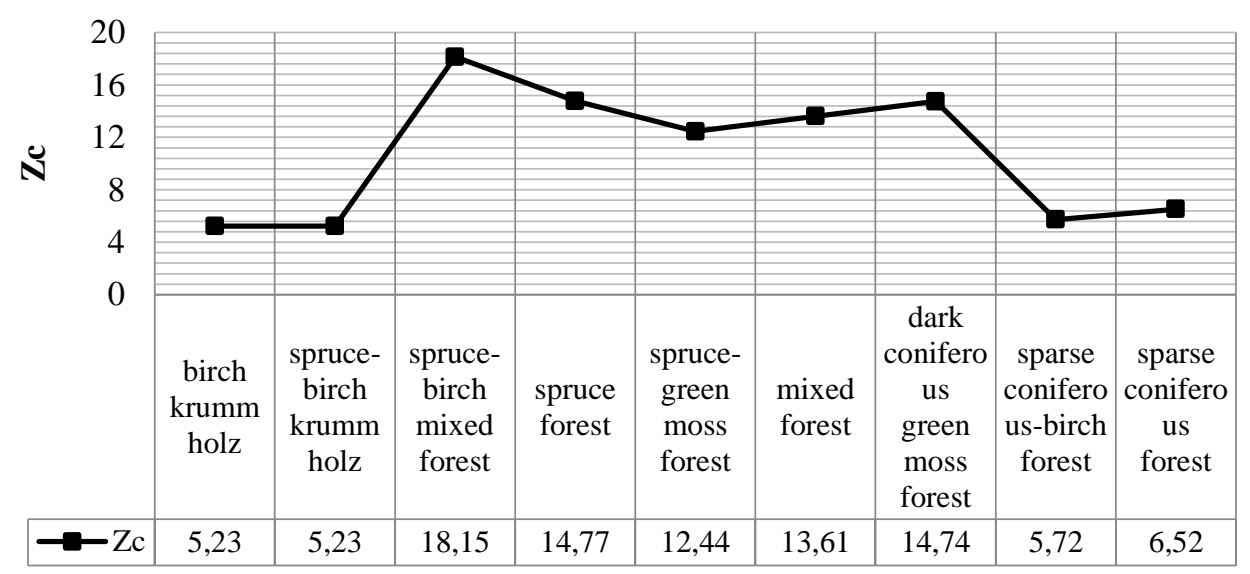

Fig. 4. Total heavy metal chemical pollution of soils from the iron ore deposit

The most important part of the research was the determination of the impact of mining waste dumps on soils. The heavy metal content in soils of sampled plots is shown in Fig. 59. The element content values were transformed to one order by raising to the power (the content of $\mathrm{V}, \mathrm{Ni}, \mathrm{Cu}$, and $\mathrm{Zn}$ is equal to $\mathrm{X} \mathrm{mg} / \mathrm{kg} \times 10-1$; the content of $\mathrm{Mn}$ is $\mathrm{X} \mathrm{mg} / \mathrm{kg} \times 10-2$, $\mathrm{Cd}-\mathrm{X} \mathrm{mg} / \mathrm{kg} \times 101$; the content of As and $\mathrm{Pb}$ didn't change).

Fig. 5 shows the content of heavy metals in soils affected by mine waste dump 6 with the following series: $\frac{M n}{623}>\frac{V}{259}>\frac{C u}{112}>\frac{Z n}{73}>\frac{N i}{47}>\frac{P b}{16}>\frac{A s}{6.1}>\frac{C d}{0.5}$.

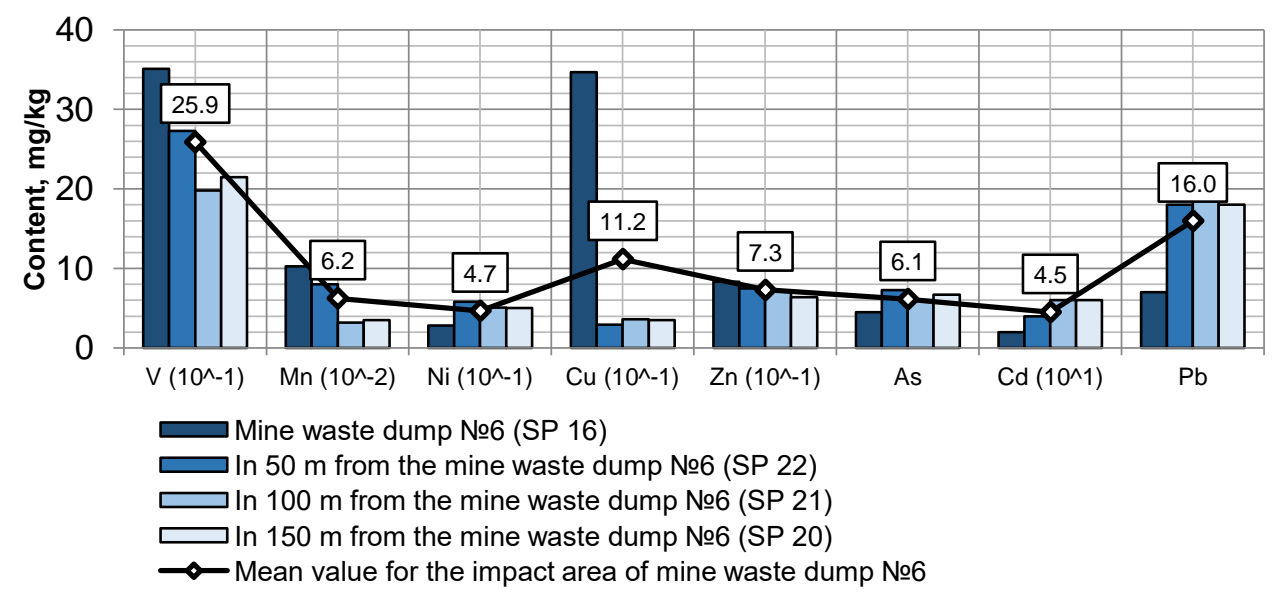

Fig. 5. Heavy metal content in soils affected by mine waste dump Nr. 6

We can observe the decrease in the content of $\mathrm{V}, \mathrm{Mn}$, and $\mathrm{Zn}$ with increasing distance between sample plots and the mine waste dump (50, 100, and $150 \mathrm{~m}$ ), as shown in Fig. 3. High content of $\mathrm{Cu}$ is noted only in the plot on the territory of the mine waste dump itself. $\mathrm{Ni}, \mathrm{As}, \mathrm{Cd}$, and $\mathrm{Pb}$ tend to increase in content with increasing distance from the dump. We can state, therefore, that the impact of mine waste dump 6 leads to an increase in lithophile $(\mathrm{Mn}$ and $\mathrm{V}$ ) and chalcophile $(\mathrm{Zn}$ and $\mathrm{Cu}$ ) concentrations.

Fig. 6 shows the content of heavy metals in soils affected by mine waste dump 4 with the following series: $\frac{M n}{623}>\frac{V}{259}>\frac{C u}{112}>\frac{Z n}{73}>\frac{N i}{47}>\frac{P b}{16}>\frac{A s}{6.1}>\frac{C d}{0.5}$. 


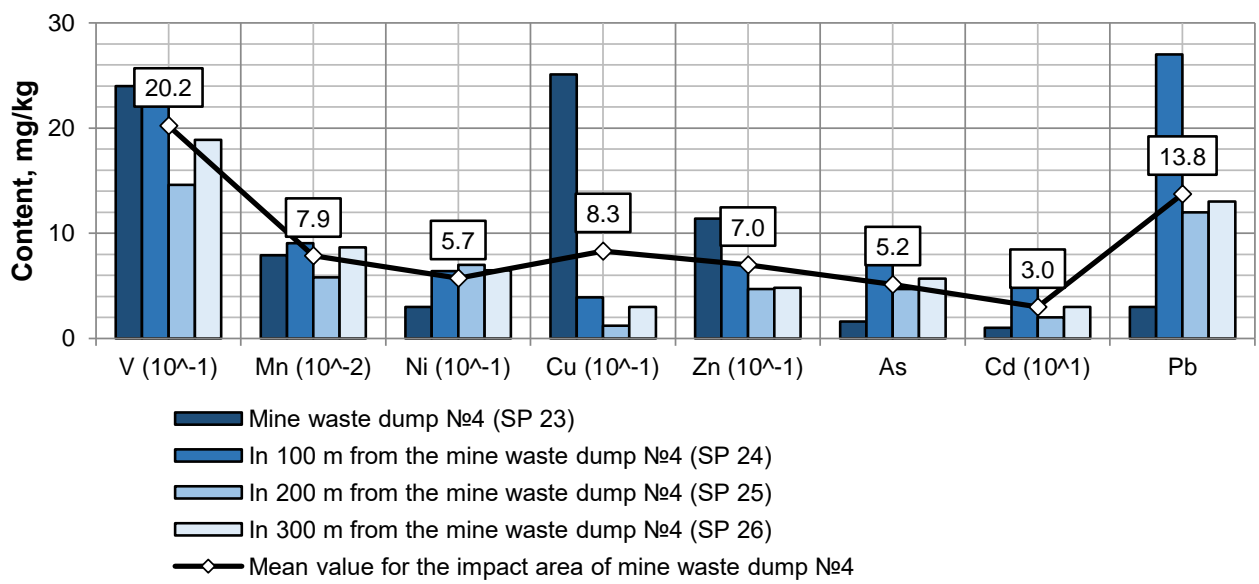

Fig. 6. Heavy metal content in soils affected by mine waste dump Nr. 4

The pattern of heavy metal distribution relative to mine waste dump 4 shown in Fig. 6 is similar to that for dump 6 (Fig. 5). With increasing distance from the mine waste dump, a reduction in $\mathrm{V}, \mathrm{Mn}, \mathrm{Cu}, \mathrm{Zn}$, and $\mathrm{Pb}$ content is observed. The greatest difference is seen for $\mathrm{Cu}$.

Fig. 7 shows the data for heavy metal content in several sampling plots, including mine waste dump 1, 7, and the site that is $200 \mathrm{~m}$ from the quarry. Geochemical patterns for the soils of the dumps 1 and 7 are different only in the content of $\mathrm{Ni}$ and $\mathrm{Zn}$.

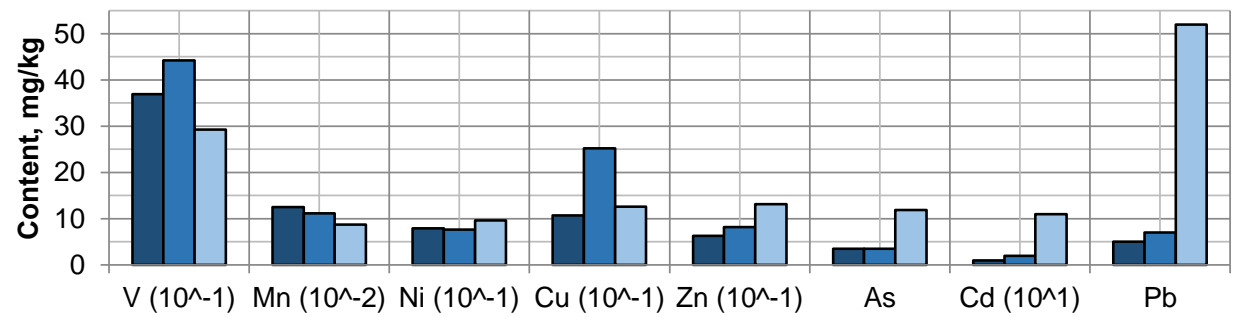

口Mine waste dump №1 (SP 31) םMine waste dump №7 (SP 27) $\square \ln 200 \mathrm{~m}$ from the quarry (SP 32)

Fig. 7. Heavy metal content in soils affected by mine waste dumps Nr.1 and Nr.7 (soils taken $200 \mathrm{~m}$ from the quarry)

The following two geochemical series for the impact area of mine waste dump 1 and for mine waste dump 7 have mixed character in general, with prevalence of lithophiles (Mn and V) and chalcophiles ( $\mathrm{Zn}$ and $\mathrm{Cu}): \frac{M n}{1253}>\frac{V}{369}>\frac{C u}{107}>\frac{N i}{79}>\frac{Z n}{63}>\frac{P b}{5}>\frac{A s}{3.5}>\frac{C d}{0.1}$ and $\frac{M n}{1119}>$ $\frac{V}{442}>\frac{C u}{252}>\frac{Z n}{82}>\frac{N i}{76}>\frac{P b}{7}>\frac{A s}{3.5}>\frac{C d}{0.2}$.

The distribution of heavy metals in soils affected by mine waste dump 2 is shown in Fig. 8. As the distance from the mine waste dump increases, a reduction in $\mathrm{V}, \mathrm{Mn}, \mathrm{Ni}$, and $\mathrm{Zn}$ is observed. The content of $\mathrm{Cu}, \mathrm{As}, \mathrm{Cd}$, and $\mathrm{Pb}$ tends to increase as the distance from the mine waste dump increases. 


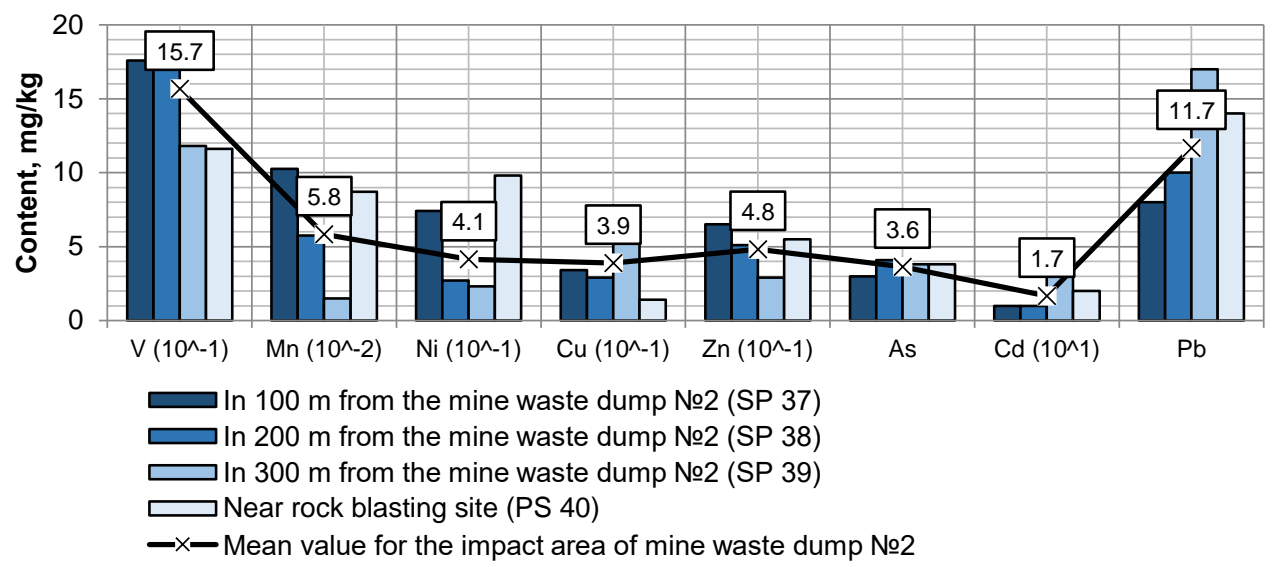

Fig. 8. Heavy metal content in soils affected by mine waste dump Nr.2

The following geochemical series for the impact area of mine waste dump 2 has primarily lithophiles, but their content is significantly less than in the impact areas of other dumps:

$\frac{M n}{583}>\frac{V}{157}>\frac{Z n}{48}>\frac{N i}{41}>\frac{C u}{39}>\frac{P b}{12}>\frac{A s}{3.6}>\frac{C d}{0.2}$. It should also be noted that there is a steep increase in the content of several elements near the rock blasting site. The geochemical series for this area is the following:

$\frac{M n}{871}>\frac{V}{116}>\frac{N i}{98}>\frac{Z n}{55}>\frac{C u}{14}=\frac{P b}{14}>\frac{A s}{3.8}>\frac{C d}{0.2}$. Here, we can see the large content of lithophiles and chalcophiles, in particular $\mathrm{Mn}, \mathrm{Ni}$, and $\mathrm{Zn}$.

The southern deposit (Fig. 9) does not affect accumulation of heavy metals in soils in a notable way. The content of all the elements decreases as the distance from the deposit increases. The following series $\frac{M n}{535}>\frac{V}{176}>\frac{Z n}{49}>\frac{N i}{41}>\frac{C u}{18}>\frac{P b}{13}>\frac{A s}{4.1}>\frac{C d}{0.2}$ for the impact area of the southern deposit is lithophilous, with Mn and V most prevalent: $\frac{M n}{535}>\frac{V}{176}>\frac{Z n}{49}>$ $\frac{N i}{41}>\frac{C u}{18}>\frac{P b}{13}>\frac{A s}{4.1}>\frac{C d}{0.2}$.

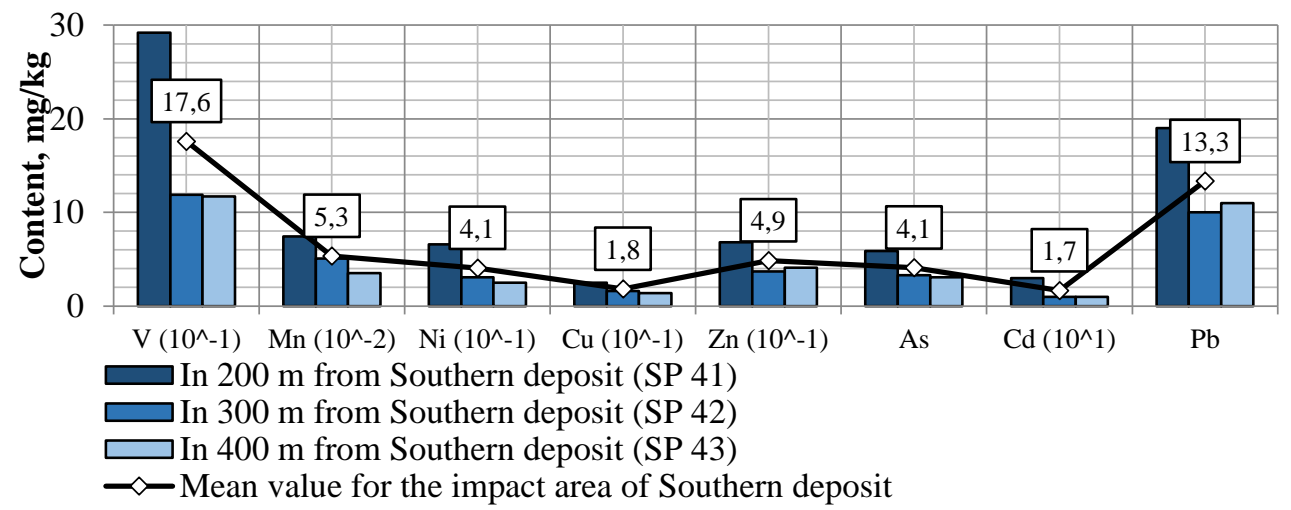

Fig. 9. Heavy metal content in soils affected by of Southern deposit

The total pollution of soils with heavy metals (Fig. 10) exceeds the permissible level (16) in the territory under the influence of the quarry ( $200 \mathrm{~m}$ from the quarry), in the territory of mine waste dumps 6 and 7. We can suggest maximum levels of heavy metal contamination in the sites closest to mine waste dumps, and there is a decrease in those levels when moving away from these dumps. 
Mean value for the impact area of Southern deposit In $400 \mathrm{~m}$ from Southern deposit (SP 43) In $300 \mathrm{~m}$ from Southern deposit (SP 42) In $200 \mathrm{~m}$ from Southern deposit (SP 41) Near rock blasting site (PS 40) Mean value for the impact area of mine waste dump №2 In $300 \mathrm{~m}$ from the mine waste dump №2 (SP 39) In $200 \mathrm{~m}$ from the mine waste dump №2 (SP 38) In $100 \mathrm{~m}$ from the mine waste dump №2 (SP 37) In $200 \mathrm{~m}$ from the quarry (SP 32) Mine waste dump №1 (SP 31) Mine waste dump №7 (SP 27) Mean value for the impact area of mine waste dump №4 In $300 \mathrm{~m}$ from the mine waste dump №4 (SP 26) In $200 \mathrm{~m}$ from the mine waste dump №4 (SP 25) In $100 \mathrm{~m}$ from the mine waste dump №4 (SP 24) Mine waste dump №4 (SP 23) Mean value for the impact area of mine waste dump №6 In $50 \mathrm{~m}$ from the mine waste dump №6 (SP 22) In $100 \mathrm{~m}$ from the mine waste dump №6 (SP 21) In $150 \mathrm{~m}$ from the mine waste dump №6 (SP 20)

Mine waste dump №6 (SP 16)

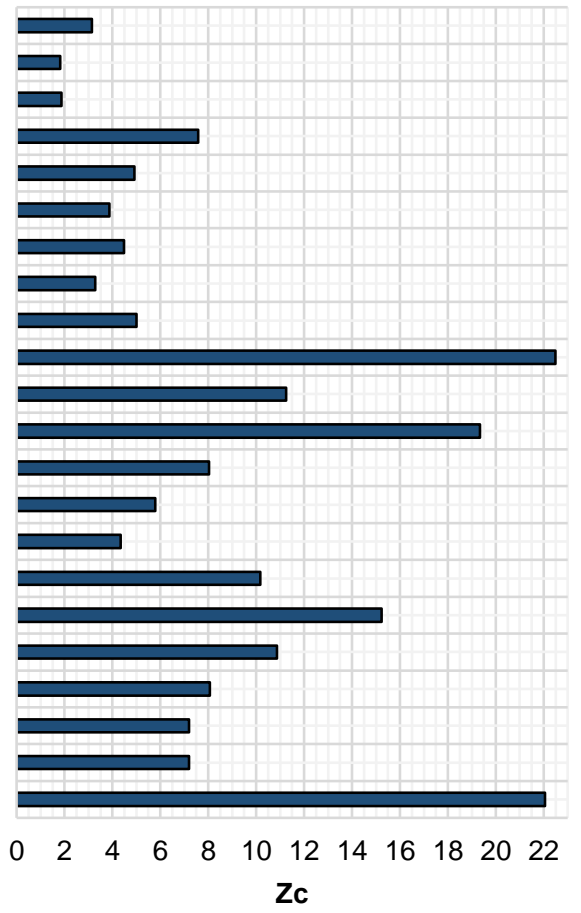

Fig. 10. Total chemical pollution of soils with heavy metals

Fig. 11 shows the content of heavy metals affected due to gold mining. We note a steep increase in heavy metal content compared to the other mine waste dumps. The following average series for the gold mining affected territory has mixed accumulation patterns with prevailing lithophiles and siderophiles:

$$
\frac{M n}{2624}>\frac{N i}{650}>\frac{V}{143}>\frac{Z n}{64}>\frac{C u}{42}>\frac{P b}{11}>\frac{A s}{9}>\frac{C d}{0.2} \text {. }
$$

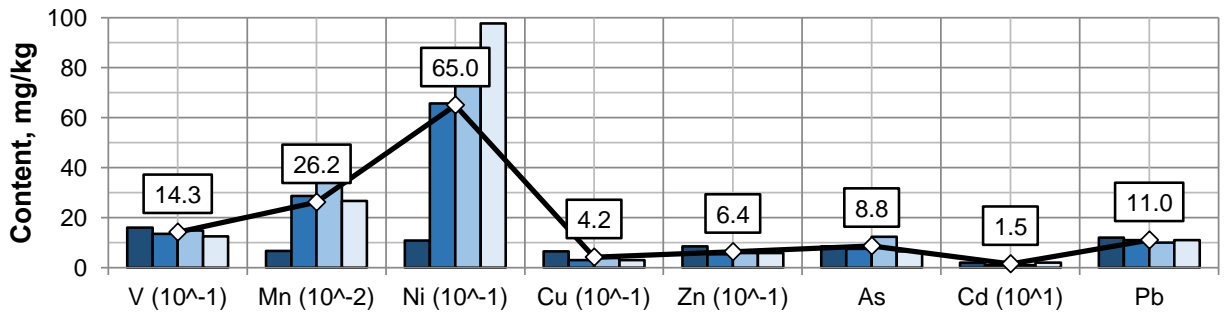

$\longrightarrow$ Verkh-Is vig. $\square$ in 100 m from Kos'ya r. $\square$ r. Kos'ya, a bank $\checkmark$ the mean for the impact area $\longleftarrow$ in 50 m from Kos'ya r.

Fig. 11. Heavy metal content in soils affected by gold mining

The largest level of total soil pollution with heavy metals (Fig. 12) was found near the Kosya River (50 and $100 \mathrm{~m}$ away). Exceedance of this index was not revealed in the site near. Verkh-Is settlement, while other sites were found to be far beyond that level. 
the mean for the impact area in $100 \mathrm{~m}$ from Kos'ya $\mathrm{r}$. in $50 \mathrm{~m}$ from Kos'ya $\mathrm{r}$.

r. Kos'ya, a bank

Verkh-ls vig.

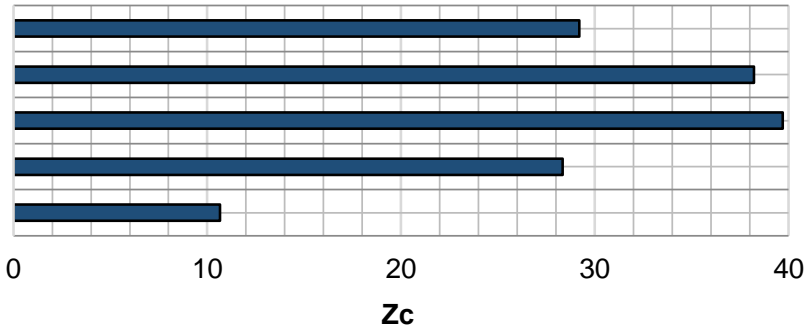

Fig. 12. Total heavy metal chemical pollution of soils affected by gold mining

The analysis of the influence of gold mining on the elementary composition of soil revealed that the content of $\mathrm{Mn}$ and $\mathrm{Ni}$ increased considerably.

We also discovered moderately hazardous pollution of Ural soils with $\mathrm{V}, \mathrm{Ni}, \mathrm{Zn}$, and As, which is connected with an increase in their natural levels.

In addition to samples from natural soils, the samples from disturbed lands were also assessed. The largest total pollution index was observed for dumps formed by dredging operations of gold mining in the past (gold mining waste dumps). These dumps are unremediated windrows with heights of $1.5 \mathrm{~m}$. The surface of the windrows is partially covered with grass. A fine-grained soil with $20 \mathrm{~cm}$ thickness accumulated in the swale features. Today, these areas are occupied by secondary mixed forests.

Moderately hazardous pollution was also observed in the grounds of the overburden waste dumps 4 and 6, which were formed as the result of mining of the deposit.

We found an insignificant exceedance of the MAC (Minimal Allowable Level; less than $2 \mathrm{MAC}$ ) for Mn and of the TAC (tentative allowable concentration; less than $2 \mathrm{TAC}$ ) for $\mathrm{Cu}$, $\mathrm{Zn}, \mathrm{Cd}$, and $\mathrm{Pb}$ in natural soils, which is caused by natural features of the area. The natural background for $\mathrm{V}$ and As exceeds the MAC, which led to the exceedance of the regulation values of $\mathrm{V}$ in all samples and As in the majority of samples. The natural background is close to the TAC value for $\mathrm{Ni}$, which is the reason why the regulation value was exceeded in a large amount of samples.

\section{Conclusion}

The mining of iron ore deposits occurs in territories where cambisols are prevalent (mountain and forest cambisols) or in mountain and forest non-podzolized soils with limited distribution of podzols. The morphology of mountain soils is unique - they are negligibly differentiated or differentiated in a way that they cannot be clearly distinguished, and they are highly gravelly. Primitive accumulative soils of the upper parts of the slopes and mountain forest cambisols are formed due to xeromorphous pedogenesis and weathering conditions.

The average geochemical series for all the phytocenosises could be presented as the following:

$\frac{M n}{676}>\frac{V}{242}>\frac{Z n}{83}>\frac{N i}{36}>\frac{C u}{33}>\frac{P b}{32}>\frac{A s}{8}>\frac{C d}{0.7}$. This series is characterized by high concentrations of $\mathrm{V}, \mathrm{Zn}, \mathrm{Ni}, \mathrm{Pb}$, and $\mathrm{As}$, and quite low concentrations of Mn. Gold mining of the area creates the following mixed geochemical series with high content of $\mathrm{Mn}$ and $\mathrm{Ni}$ across the territory of the deposit: $\frac{M n}{2624}>\frac{N i}{650}>\frac{V}{143}>\frac{Z n}{64}>\frac{C u}{42}>\frac{P b}{11}>\frac{A s}{9}>\frac{C d}{0.2}$.

$\mathrm{Z}_{\mathrm{c}}$ values in soils around the iron ore deposit are changing from permissible to moderately hazardous. It was revealed that regulation values of $\mathrm{V}$, As, and $\mathrm{Ni}$ were exceeded, which could be explained by the increased geochemical background in the area. An increased Cd and $\mathrm{Pb}$ content relative to background was observed for Ural soils near the quarry. 


\section{References}

1. V.I. Vernadsky, Chemical Structure of the Earth's Biosphere and its Environment (Nauka, Moscow, 2001) (in Russian)

2. V.A. Alekseenko, Ecological Geochemistry (Logos, Moscow, 2000) (in Russian)

3. V.A. Alekseenko, A.V. Suvorinov, V.A. Alekseenko, \& A.B. Bofanova, Metals in the Environment. The Soils of Geochemical Landscapes of Rostov Region (Logos, Moscow, 2002) (in Russian)

4. V.A. Alekseenko, S.A. Buzmakov \& M.S. Panin, Geochemistry of Environmental: monograph for schools (Perm state university, Perm, 2013) (in Russian)

5. S.A. Buzmakov, Y.V. Khotyanovskaya, Applied Geochemistry, 113, 104443 (2020)

6. S.A. Buzmakov Vestn. Perm. Gos. Univ., Biol., 2, 133-138 (2004). (in Russian)

7. S.A. Buzmakov, Geographical bulletin, 4(23), 46-50 (2012). (in Russian)

8. L. Angelovičová, L. Bobul'ská \& D. Fazekašová, Carpathian J. of Earth and Environmental Sciences, 10(1), 193-201 (2015)

9. A. Kelepertsis, A. Argyraki,, \& D. Alexakis, Geochemistry: Exploration, Environment, Analysis, 6(4), 349-355 (2006)

10. V.I. Golik, O.N. Polukhin, A.N. Petin \& V.I. Komachshenko, Mining J., 4, 91-98 (2013). (in Russian)

11. R.A. Wuana, \& F.E. Okieimen, ISRN Ecology, 2011, 1-21 (2011).

12. Adriano, D.C., Trace Elements in Terrestrial Environments: Biogeochemistry, Bioavailability and Risks of Metals (Springer, New York, 2003)

13. G.A. Teplaya, Astrakhan bull. of ecol. education, 1(23), 182-192 (2013). (in Russian)

14. V.V. Ivanov The geochemistry of the dispersed elements $\mathrm{Ga}, \mathrm{Ge}, \mathrm{Cd}$, In and TI in hydrothermal deposits (Nedra, Moscow, 1966)

15. S.E. Deryagina, O.V. Astaf'eva \& A.N. Medvedev, Nature management economics, 1, 24-30 (2013) (in Russian)

16. V.I. Golik, V.I. Komachshenko \& A.V. Polikov, Izvestiya of the Tula State University. Sciences of Earth., 1, 100-110 (2016) (in Russian)

17. G. A. Vostroknutov, Temporary methodological guideline on conducting geochemical surveys during geo-ecological works (Ekaterinburg, 1991) (in Russian)

18. Yu.E. Sayet, B.A. Revich \& E.P.Yanin, Environmental Geochemistry (Nedra, Moscow, 1990) (in Russian)

19. R.S. Zubareva \& V.P. Firsova On soil characteristics in spruce forests of the mountain band in the Middle Ural region. Soils and hydrologic regime of Ural forests (UF AN SSSR, Sverdlovsk, 1963) (in Russian)

20. Methodological recommendation for identification of degraded and polluted lands, (Russian Federal Environmental Informational Agency, Moscow, 1996) (in Russian)

21. SanPiN 2.1.7.1287-03. Sanitary and Epidemiological Requirements with Respect to Soil Quality (Moscow, 2003) (in Russian)

22. SanPiN 4266-87. Methodological instructions for assessing the degree of danger of soil contamination with chemicals (Moscow, 1987) (in Russian)

23. S.V. Grigoryan, A.P. Solovrv \& M.F.Kuzin, Instruction on Methods of Geochemical Prospecting of Ore Deposits (Nedra, Moscow, 1983). (in Russian)

24. B.A. Lebedev, Agrochemical characteristics of the USSR soils (Nauka, Moscow, 1964) (in Russian)

25. A.P. Solovov \& A.A. Matveev, Geochemical prospecting methods of ore deposits (Moscow State University Publ., Moscow, 1985) (in Russian)

26. V. P. Firsova Soils of Sverdlovsk oblast and their changes under the influence of forestry practices. Institute of plant and animal ecology, (RAS, Sverdlovsk, 1969. (in Russian)

27. I.S. Urusevskaya, Eurasian Soil Science, 40(11), 1145-1157 (2007). (in Russian) 